Flying beneath the clouds at the edge of the world: using a hexacopter to supplement abundance surveys of Steller sea lions (Eumetopias jubatus) in Alaska

\begin{tabular}{|r|l|}
\hline Journal: & Journal of Unmanned Vehicle Systems \\
\hline Manuscript ID & juvs-2015-0010.R1 \\
\hline Manuscript Type: & Article \\
\hline Date Submitted by the Author: & 21 -Oct-2015 \\
\hline Complete List of Authors: & $\begin{array}{l}\text { Sweeney, Kathryn; AFSC, NMFS, NOAA, NMML } \\
\text { Helker, Van; AFSC, NMFS, NOAA, NMML } \\
\text { Perryman, Wayne; NOAA, Southwest Fisheries Science Center; NOAA, } \\
\text { SWFSC, Marine Mammal and Turtle Division } \\
\text { LeRoi, Donald; Aerial Imaging Solutions, } \\
\text { Fritz, Lowell; AFSC, NMFS, NOAA, NMML } \\
\text { Gelatt, Tom; AFSC, NMFS, NOAA, NMML } \\
\text { Angliss, Robyn; NOAA, National Marine Fisheries Service }\end{array}$ \\
\hline Keyword: & UAS, multi-rotor, Steller sea lion, abundance, wildlife \\
\hline \multicolumn{2}{|c}{} \\
\hline
\end{tabular}




\title{
1 Flying beneath the clouds at the edge of the world: using a hexacopter to supplement abundance surveys of Steller sea lions (Eumetopias jubatus) in Alaska
}

\author{
Kathryn L. Sweeney ${ }^{1}$, Van T. Helker ${ }^{1}$, Wayne L. Perryman ${ }^{2}$, Donald J. LeRoi ${ }^{3}$, Lowell W. Fritz ${ }^{1}$, Tom S.
} Gelatt ${ }^{1}$, and Robyn P. Angliss ${ }^{1}$

Keywords: UAS, multi-rotor, Steller sea lion, abundance, wildlife

Abstract: Aerial imagery is the most effective method National Marine Fisheries Service (NMFS) uses to assess abundance of Steller sea lions (Eumetopias jubatus). These images are traditionally captured from occupied aircraft, but the long distances between airfields along the 1,900 km Aleutian Island chain, inclement weather during the survey season, and dangerous winds at sites adjacent to cliffs severely limit flying opportunities. Due to the pressing need for current trend information for a population in persistent decline we turned to a small unoccupied aircraft system (UAS), an APH-22 hexacopter. Our primary objective was to supplement traditional aerial surveys during the annual abundance survey. The second objective was to test whether the resolution of images captured with the hexacopter were adequate for sighting permanently marked individuals. From June-July 2014, NMFS biologists based on a research vessel assessed sites from Attu Island to the Delarof Islands $(n=23)$, surveying sites from land $(n=12)$ and with the hexacopter $(n=11)$. Simultaneously, Traditional aerial surveys were conducted east of the Delarof Islands $(n=172)$. This combined approach enabled us to conduct the most complete survey of adult, juvenile, and newborn Steller sea lions in the Aleutian Islands since the 1970s. Images collected also allowed for us to identify alpha-numeric permanent hexacopter to supplement future surveys.

\footnotetext{
${ }^{1}$ National Marine Mammal Laboratory, Alaska Fisheries Science Center-National Marine Fisheries Service-NOAA, 7600 Sand Point Way NE, Seattle, WA 98115

${ }^{2}$ Protected Resources Division, Southwest Fisheries Science Center-National Marine Fisheries Service-NOAA, 8901 La Jolla Shores Dr., La Jolla, CA 92037

${ }^{3}$ Aerial Imaging Solutions, 5 Myrica Way, Old Lyme, CT 06371
} 


\section{Introduction}

The National Marine Fisheries Service (NMFS, National Oceanic and Atmospheric Administration) is mandated by the Marine Mammal Protection Act and the U.S. Endangered Species Act to monitor the status of the endangered western population of Steller sea lions (Eumetopias jubatus) in Alaska. Since the 1970s NMFS has used occupied ("manned") fixed-wing aircraft to conduct abundance surveys. This has proven to be the most effective method for collecting counts to estimate abundance and monitor population trends (NMFS 2008). However, these traditional aircraft surveys in Alaska have proven to be quite difficult, especially along the 1,900 $\mathrm{km}$ of the Aleutian Island chain which is only serviced by three airfields (Fritz et al. 2008, 2013). In addition to scarce and remote airfields, high winds at sea lion sites adjacent to cliffs pose a danger to occupied aircraft, and inclement weather (e.g., fog and low cloud ceilings) routinely ground the survey team or prohibit the surveying of large areas. In fact, during the 2012 aerial survey, the survey team spent 18 days on Shemya Island (the farthest west airfield in the Aleutian Islands) but could only survey one day due to fog and low ceilings. Similarly, many sea lions sites within the Rat Island group just east of Shemya had not been surveyed since 2008. Obtaining regular estimates of abundance for Steller sea lions in the western Aleutian Islands is particularly important because NMFS has observed continued population declines in this region resulting in regulations restricting activities of economically important commercial fisheries from 2010 to 2014 (NMFS 2010; Fritz et al. 2013; Johnson and Fritz 2014).

Unoccupied aircraft systems (UAS) are novel innovations and their recent applications for ecological studies have simplified, improved safety of biologists conducting, increased efficiency of, reduced cost of, and have even fueled in the innovation of new studies from many traditional survey methods. Multi-rotor aicraft capable of vertical take-offs and landings have been used for smaller spatial scale survey efforts and lend to portability and reduced cost (Perryman et al. 2012; Durban et al. 2015; Goebel et al. 2015; Pomeroy et al. 2015). Fixed-wing UAS has been applied for larger spatial ranges, or for carrying larger sensors or imagery payloads (Hodgson et al. 2013; Vermeulen et al. 2013; Moreland et al. 2015). Jones et al. (2006) explained that the use of UAS for wildlife studies requires a field tool that is easy-to-use, electric-powered, hand-launched, easy to transport, and operable by one or two people.

The APH-22 was built for the high resolution imagery payload, ideal for the capture of high-resolution images. This platform has the qualities that are required for our wildlife studies (i.e., easy-to-use, electric powered, hand-launched, easy to transport, and operable by one or two people; Jones et al. 2006). Previous testing with a multi-rotor and fixed wing UAS led to our selection of the APH-22 multi-rotor UAS (Aerial Imaging Solutions, Old Lyme, CT), based on the repeated successes of the NMFS Southwest Fisheries Science Center employing the hexacopter in Antarctica (Perryman et al. 2012; Goebel et al. 2015). The ability to fly multi-rotor aircrafts in any direction and hover in one place allows for precise positioning over areas of interest for an extended period of time and enables the pilot to control the UAS comfortably even while in close proximity to cliffs adjacent to sea lion sites. A hexacopter has the advantage of more stability in flight and an increase in power by about $50 \%$ for a $15 \%$ increase in weight when compared to similar quadrocopters. Hexacopters also produce less noise than quadrocopter platforms (Perryman et al. 2012) and can be landed safely after the loss of one, or even two, engines.

The manufacturer integrated a fixed, high resolution camera that met our imaging specifications in order to capture images at higher altitudes $(\geq 45 \mathrm{~m})$ mandated by the marine mammal permit for Steller sea lion- 

aircraft surveys and are of higher resolution than those collected from other platforms tested. The verticallymounted camera would also allow NMFS scientists to use the images for future photogrammetric studies (Goebel et al. 2015; Sweeney et al. 2015). Maintaining positional control, a feature of multi-rotor aircraft, means reduced horizontal motion or vibration thereby reducing image blur. These hexacopters have proven to be exceptionally reliable, easy to fly, and at roughly $\$ 25,000$ a system they are available at a price point we can support. By training scientists to fly this aircraft system we could save additional costs by not having to take additional team members into the field to function only as pilots, which is a clear benefit when the number of research vessel berths are limited.

The primary objective of this study was to mitigate the challenges faced during traditional aircraft surveys in the Aleutian Islands (remote and sparse airfields, and inclement weather greatly reducing survey time) by using an UAS to supplement these surveys in order to fill in the gaps of missing abundance information in this critical area of study. Additionally, we wanted to test how adequately the imagery payload could be used to capture aerial images of permanently marked individuals for long-term life history studies.

\section{Material and methods}

\section{Previous testing of UAS platforms}

In March 2012, NMFS biologists and designated UAS pilots tested the efficacy of a multi-rotor and a fixed wing unoccupied aerial platforms for counting sea lions in the western Aleutian Islands. This survey was not conducted during the breeding season to contribute to abundance surveys but to test the efficacy of UAS in remote areas and for photographing Steller sea lions. The Aeryon Scout (Aeryon Labs, Inc.; "Scout") is a small battery-powered, four-motor multi-rotor (quadrocopter) aircraft equipped with a GoPro camera affixed to a gimbal mount to capture either high resolution video or still images. At the time of this testing, the Scout was estimated to cost well over $\$ 100,000$. The Puma (AeroVironment, LLC.) is a fixed-wing (approximately $3 \mathrm{~m}$ wingspan), battery-powered aircraft with imagery equipment integrated to capture real-time video as well as still and infrared images. The Puma is significantly less portable than the APH-22 hexacopter and takes a team of operators that are likely not biologist. Personnel operated the Scout from land or from the research vessel while the Puma flight team conducted operations from the vessel (though it could operate from land) but was recovered by landing in the water.

Scout pilots conducted 30 flights at 16 sea lion sites however; complete counts were only collected from images captured at four sites due to incomplete site coverage and low resolution of images and/or video. Puma pilots flew nine missions at nine sites though images and/or video were too low resolution to use for complete counts and only a partial count was collected for one site. Due to the haul-out behavior of sea lions (lying within close proximity to each other) complete counts could not be collected from the infrared images. Because the flight missions were not conducted within the breeding season (i.e., when newborn sea lions, or pups, were present) and were performed to investigate the reactions of Steller sea lions to UAS, permitted altitudes allowed for Scout flights ranged from approximately 15 to $25 \mathrm{~m}$. This altitude range is much lower than the finalized minimum altitude ( $\geq 45 \mathrm{~m}$ ) allowed for Steller sea lions UAS operations (as specified under 
Puma surveys ranged from approximately 60 to $152 \mathrm{~m}$. While animals with permanent marks were visible from images, analysts could not decipher alpha-numeric marks due to low image resolution. The images collected with the hexacopter are comparable to those collected during traditional aircraft surveys and are of higher resolution than those collected from the Scout or Puma in 2012 (Fig. 1).

\section{Study area and field studies}

Aerial survey effort was focused in the Aleutian Island chain due to incomplete survey coverage in previous years and the continued decline in Steller sea lion abundance in the western portion of the chain (Fritz et al. 2013; Johnson and Fritz 2014). Abundance surveys are conducted during the peak of the Steller sea lion breeding season when the greatest proportions of adult and juvenile (non-pup) sea lions haul-out on known terrestrial sites to breed and birth pups. Surveys occur from late June to mid-July when newborn sea lions (pups) are approximately 1-month old and remain on land (Pitcher and Calkins 1981; Pitcher et al. 2001).

The Island chain was divided geographically between two survey platforms. Biologists, including the hexacopter crew, based on the U.S. Fish and Wildlife Service research vessel Tighlâx from 18 June to 3 July 2014 focused on the western portion of the chain, from Attu Island (172 $27^{\prime}$ E) to Amchitka Pass (180 ; Fig. 2). Simultaneously, NMFS biologists working from a NOAA Twin Otter (DeHavilland DHC-6) operated by the Aircraft Operations Center in Tampa, FL, surveyed east of Amchitka Pass to the Shumagin Islands $\left(157^{\circ} \mathrm{W}\right)$ from 23 June to 9 July 2014.

We coordinated surveys between the aerial platforms for sites in the Delarof Island group to compare counts during the same time period. Unfortunately, high winds aloft (11-12 m/s on the ground, approximately $15 \mathrm{~m} / \mathrm{s}$ aloft) prevented complete hexacopter surveys of Gramp Rock, Ilak and Column Rocks (Amchitka Island) whereas patchy fog impeded the occupied aircraft from conducting a complete survey of Hasgox Point (Ulak Island) during the time period when both platforms could overlap (29-30 June). However, the occupied aircraft surveyed Hasgox Point on 9 July, 10 days after the hexacopter survey (29 June). Both platforms did survey Gramp Rock however, the hexacopter survey (30 June) was incomplete due to high winds, and the occupied aircraft conducted their survey 9 days later ( 9 July).

Counts were conducted between 1000 and 1900 Alaska Daylight Time when sea lions are present on land in greatest numbers (Chumbley et al. 1997; Sease and Gudmundson 2002) and lighting conditions are optimal for photography (Fritz et al. 2013). Observers based on the research vessel conducted land-based counts ("land counts") from the vessel, an inflatable skiff offshore, or from land for those sites with less than 40 sea lions hauled out. We used the hexacopter to capture aerial images of those sites with greater than 40 sea lions hauled out, or those sites where visual obstructions or terrain prevented the land-based observers from conducting a complete count. When terrain allows it, complete visual counts of sea lions sites are manageable when there are less than 40 individuals present.

\section{Unoccupied aircraft, ground station, and camera systems}

The APH-22 is an electric 6-motor multi-rotor aircraft, commonly referred to as a hexacopter. It measures $82.3 \mathrm{~cm}$ from rotor tip to rotor tip and weighs approximately $1.72 \mathrm{~kg}$ without the lithium polymer battery or camera payload (Perryman et al. 2012; Fig. 3). The APH-22 can reach speeds up to $15 \mathrm{~m} / \mathrm{s}$ or hover in place. The payload allowance is $0.998 \mathrm{~kg}$, which is sufficient to accommodate a high resolution digital camera. 
144 We selected the Canon EOS M (18 megapixel, mirrorless camera) equipped with a EF-M f/2 STM $22 \mathrm{~mm}$ pancake lens. This camera and lens offers a minimum resolution of about $1-1.2 \mathrm{~cm} /$ pixel at approximately $45 \mathrm{~m}$ altitude. The manufacturer created a fixed, vertically oriented camera mount underneath the body of the UAS. We tested various camera settings in a variety of light levels and wind speeds using a tri-bar resolution target and achieved the highest imagine resolution.

The hexacopter transmits data and video to a ground station. A small LCD screen displays telemetry information from the hexacopter including: distance and altitude from the take-off location, heading, GPS fix quality, battery voltage of the hexacopter, and the length of time the motors have been running. A second larger screen displays real time video from the digital camera mounted on the hexacopter. This enables the hexacopter crew to see what the hexacopter is positioned over and when the camera is firing. A series of LEDs on the ground station indicate whether the altitude, position hold, or the "come home" features are engaged.

The hexacopter crew consisted of two trained pilots who took turns with the roles required for flights. The pilot in command flew the hexacopter while a visual observer watched the surrounding airspace for other aircraft. The hexacopter crew maintained visual contact with the hexacopter but were not always able to maintain visual contact with animals onshore. During all flights, a team of at least two biologists were positioned to observe the animals and record any reaction from the hexacopter. The pilots maintained a survey altitude from 45 to $60 \mathrm{~m}$ for all flights over animals. Altitude varied due to terrain and sea lion behavior.

The hexacopter was controlled by a pilot using a 10-channel hand-held radio controller (RC), where the sticks are used to manipulate throttle, pitch, roll, and yaw and switches are used to engage auxiliary functions. Pilots are able to command the hexacopter to hold altitude, hold position, or "come home" which commands the hexacopter to return to the take-off location and hover. Another switch triggers the camera to take pictures at either of the two pre-programmed time intervals ( 5 or $10 \mathrm{~s}$ for our study). Under our Certificate of Authorization from the Federal Aviation Administration, we are unable to fly when wind speeds on the ground exceed 12.86 $\mathrm{m} / \mathrm{s}$ and in rainy conditions. Finally, an additional control allows the pilots to simulate a failure of RC connection with the aircraft ("lost link"). In the event of a lost link, the aircraft will return to the take-off location and land.

\section{Occupied aircraft surveys}

Biologists installed a camera mount equipped with three Canon EOS-5D Mark III cameras (21 megapixel, full-frame sensor) in the aircraft belly port and conducted the survey under the same methods described in Fritz et al. (2013). The cameras are installed in a mount developed by Aerial Imaging Solutions that receives input on aircraft altitude and ground speed and then rocks the cameras at a rate that eliminates the image blur associated with the forward movement of the aircraft while the camera shutter is open. Image collection was initiated manually by an observer on the mount controller where capture rates are set to provide a $60 \%$ overlap between images. Survey altitude was targeted around $230 \mathrm{~m}$ but could range between 150 to $305 \mathrm{~m}$ depending on terrain, cloud ceiling, and wind conditions.

\section{Image analysis}

Aerial images of sea lion sites obtained by UAS and traditional aerial surveys were analyzed by two independent counters with the same methods described in Fritz et al. (2013). Counters used high resolution 
monitors to count sea lions from digital images collected from the UAS and occupied aircrafts using Adobe Photoshop software (mention of specific products does not serve as an endorsement). Each sea lion counted was assigned to one of the five age-sex classes (pup, juvenile, adult female, sub-adult male, and adult male or bull) based on color, size, shape, and behavior of the individual. The script in the software enables the count to be tallied for each age-sex class. Images collected with the hexacopter were also examined to sight permanently marked animals. We used agTrend to model updated trends and abundance of the population with the finalized counts from the 2014 survey (Johnson and Fritz 2014, Fritz et al. 2015).

\section{Results}

The 2014 Steller sea lion survey of the Aleutian Islands was the most complete survey of pups and non-pups since the 1970s (Fritz et al. 2008, 2013; Table 1; Fig. 4). Of the 172 known terrestrial sea lion sites along the Aleutian Island chain, 153 were successfully surveyed. Twenty of the 21 sites missed in the western portion of the Aleutian Islands by the research vessel were intentionally skipped as they have no recent (since the early 2000s) presence of sea lions (Fritz et al. 2013). Excluding these missed sites, 96\% of non-pup and $94 \%$ of the pup sites used for abundance trend analyses were surveyed (Table 2). In total, the research vessel based team surveyed 23 sites, 12 of which were visually counted by observers on land and 11 were surveyed using the hexacopter.

The hexacopter captured fewer than 1,500 aerial images of 11 sites during 17 flights. The farthest we flew the hexacopter from the take-off location was $634 \mathrm{~m}$. Mean flight time was 11 minutes and the longest flight was 16 minutes. When photographing sea lion aggregations, we generally kept the aircraft in a hover or moved at very low speeds (e.g., average speed $<2 \mathrm{~m} / \mathrm{s}$ ) to ensure complete photographic coverage of the site and reduce the impacts of forward image motion (i.e., blur) as the images were collected.

Over the course of the 17 flights totaling in almost 4 hours of flight time, there was only one instance when the observers noted a disturbance causing the sea lions to move from their position. A majority of the sea lions did not react to the presence of the hexacopter. If they did, their typical reaction was to adjust to an upright posture to look up at the sky with little or no movement from their position (Fig. 5). At Ayugadak Island we flew the hexacopter above the 87 non-pups and 42 pups. Observers at the cliff edge noted 24 animals moving from their position towards the water edge. Only five of those entered the water, but stayed in the shallows. We believe this disturbance was caused when the pilot adjusted the hexacopter altitude while over the animals. A hexacopter generates greater sound levels when changing altitude than it does in level flight and the loudness could have been further amplified by echoing off the adjacent $12 \mathrm{~m}$ cliff. Overall, the disturbance caused by the hexacopter was minimal with only 5 of total 1,589 non-pups $(0.3 \%)$ that we flew over slowly entering the water. No 'stampede' reactions by non-pups were observed during hexacopter operations. Anecdotally, we flew within close proximity to numerous seabird species in flight (e.g., gulls) and nearby nesting bald eagles at one site with no reaction observed from birds to the hexacopter in flight.

The occupied aircraft team surveyed a greater portion of the Aleutian Islands, as well as part of the western Gulf of Alaska region. They surveyed a total of 172 sites and captured over 13,500 images at 97 sites. The aircraft flew over 19,700 non-pups and disturbed approximately 1,000 (5\%) sea lions into the water. Despite its higher survey altitude, the Twin Otter has a larger silhouette in the sky and is significantly louder 
223 than the hexacopter, demonstrated by the greater disturbance rate (van Polanen Petel et al. 2006; Goebel et al. 2015).

Surveys of Point (Ulak Island) that spanned 10 days between the hexacopter and occupied aircraft indicated pups counts were similar but the non-pup count was different because areas missed by the aircraft had only non-pups present. Pup counts were similar (1-3\% difference) between all surveys which correlates with newborn pup behavior of staying on land during their first month of life (Pitcher and Calkins 1981). In contrast, the non-pup counts showed greater variation $(5 \%)$.

Optimal camera setting established from training flights were tested in the field and new settings evaluated in changing environmental conditions (e.g., wind, light levels, whitewashing of waves on the fringes of sites). We found that the highest resolution images were captured with aperture priority set between 5.0 to 5.6 and the ISO set from 800 to 1200 .

Observers searched for permanently marked individuals from the ground or skiff and the same branded animals were observed in the hexacopter images as well (Fig. 6). Two marked individuals were sighted in the aerial images that were not observed from ground observers because of

237

\section{Discussion}

The incorporation of this innovative technology coupled with traditional aerial survey methods has resulted in the most complete survey of pup and non-pup Steller sea lions Aleutian Islands in over 35 years (Fritz et al. 2008, 2013). By training scientists to operate these systems in the field we eliminate the need to take individuals into the field to act solely as pilots. This UAS can be operated from virtually any location by a flight crew of two trained biologists. The ability vertically launch and recover by hand allows for operations in areas with limited space or uneven terrain. Our decision to devote the research vessel and hexacopter crew to the most remote regions of the Aleutian Islands minimized occupied aircraft downtime, allowing the Twin Otter to cover areas serviced by more airfields and with more conducive weather conditions than the western Aleutian Islands. This allowed the occupied aircraft team to survey the western Gulf of Alaska, extending the survey farther than anticipated. The hexacopter was critical to our success in surveying the western Aleutian Island sites. However, the occupied aircraft was critical to the survey of the remainder of the Aleutian Island chain. entire survey because of technical, logistical, regulatory, and economic limitations (Vermeulen et al. 2013). An abundance survey conducted by research vessel could not be accomplished within the narrow biological window of the Steller sea lion summer breeding season or would require multiple vessels (and UASs) to cover the entire range. Chartering a research vessel, or multiple vessels, to span the entire survey-range would be costprohibitive. An abundance survey solely conducted by research vessel would be significantly more expensive than traditional aerial survey methods and would offer little benefit in areas that are serviced by multiple airfields and are prone to more conducive weather. Currently, UAS flight regulations do not support long-range, beyond line-of-sight missions at low altitudes in national airspace within close proximity to land that would be necessary for collecting images of similar resolution. Also, there isn't an UAS currently available that could operate under such conditions and meet our image resolution needs for counting Steller sea lions and reading 
As with many other reports of using an UAS for wildlife studies, we also found very little disturbance associated with our electrical rotor platform (Vermeulen et al. 2013). This allowed us to fly at low altitudes ( $\geq 45$ $\mathrm{m})$ to capture high resolution images, especially useful for identifying small, marked juveniles. Our experience with the one instance of animal disturbance taught us that aircraft altitude adjustment and horizontal movements should be made away from the animals or conducted very slowly when above the animals. This is especially important when flying at sites adjacent to cliffs which can echo the sounds of the hexacopter, especially if there is wind to direct the sound towards the animals.

While we were unable to survey any sites on the same day with both aerial platforms, we were able to compare counts for one site conducted on different days. We are confident in our ability to collect comparable counts between both aerial platforms as these systems have downward-facing cameras which capture the same vertical perspective to collect the most accurate counts. Aerial imagery from Hasgox Point shows the greatest variation in non-pup counts between platforms and survey dates while pup counts were similar. Based on haulout behavior of sea lions during the breeding season, we would expect the pup counts to be relatively constant as all flights were conducted at the end of the breeding season, well after the mean pupping date (9-11 June; Pitcher et al. 2001). It is likely that only a few pups were born in the 10 days between the hexacopter and occupied aircraft surveys. Newborn pups remain on land during their first month before taking to the water (Pitcher and Calkins 1981). However, the lower 9 July pup count could be explained by those pups born early in the season entering the water. Non-pup counts can vary more throughout the season as females and juveniles leave the site to forage. Human error by the independent counters could also contribute to variations in counts. Regardless, count variation fell within the 5\% difference or an absolute difference of less than 20 non-pups and 10 pups expected between the two independent counters (Fritz et al. 2013).

Occupied aircraft surveys benefit from an aerial perspective that allows biologists to ensure the entire site is surveyed whereas the perspective from a vessel or land can make this difficult. The vessel based crew was careful to investigate surrounding areas from the site to ensure all animals were counted. In comparing imagery obtained by the hexacopter with imagery captured by the occupied aircraft in previous years, we can confirm complete coverage of the 11 sites with the hexacopter.

The counts collected from this study show there is a continued decline in the abundance of non-pup Steller sea lions in the area of concern in the western Aleutian Islands, from Delarof Islands to Attu Island. Since year 2000, non-pups continue to decline 3.6 to $6.4 \%$ per year and pups are declining 3.2 to $9.7 \%$ per year. Regions east of the Delarof Islands (i.e., Tanaga Pass) are relatively stable or increasing (Fritz et al. 2015).

Our experiences and challenges yielded useful insights for future operations. First, a small portable UAS is exposed to numerous opportunities for minor damage associated with transport during beach landings or hikes across rugged terrain, typical in the Aleutian Islands. Spare parts and tools and the ability to perform basic repairs in the field are necessary to increase the likelihood of success. Second, winds observed at ground level are not representative of winds aloft and should be considered prior to take-off. Third, abrupt changes in hexacopter altitude or horizontal position require additional thrust and result in increased sound levels. This is especially true in higher winds. If disturbance is a concern, major adjustments in altitude or position should be made away from the animals or very slowly if it becomes necessary to adjust when the animals are nearby.

A small UAS operated by ship-based biologists was an essential component to our success during the 2014 abundance survey. We will continue to use the APH-22 as a supplemental tool for future Steller sea lion 
abundance surveys and hope to implement some changes to our protocols to improve our ability to collect aerial imagery. We intend to begin conducting flight operations from the research vessel at selected sites, eliminating the need to transport UAS equipment from ship to shore and overland prior to flying. We will also have a second APH-22 hexacopter equipped with upgraded motors to improve performance in higher wind speeds. In addition to continuing the use of UAS to collect images of Steller sea lions in the Aleutian Islands (especially to collect images of those sites missed in the 2014 survey), we also plan on expanding our operational area to include sites along coastal Oregon and California in the 2015 field season. We will also work towards using the hexacopter to update the historical photo-series depicting rookery space-use of northern fur seals (Callorhinus ursinus) on the Pribilof Islands which, has unsuccessful with occupied aircraft, despite multiple attempts. During this time, we will test the use of this platform to supplement abundance studies of northern fur seals. Planning to incorporate the use of the APH-22 in our research projects during the 2015 field season reflects our belief that a small UAS operated by biologists are an indispensable tool for collecting data that is otherwise difficult or impossible to obtain using conventional methods.

\section{Acknowledgements}

We thank the U.S. FWS for their continued support, especially the highly-skilled R/V Tiĝlâx crew and those stationed in Adak, AK. We would also like to thank the NMML ground survey crew, Brian Fadely and Jeremy Sterling for their efforts. This project would not have been possible without the NOAA Aircraft Operations Center (AOC)-UAS Section's guidance on UAS operations in U.S. airspace and their integral assistance with obtaining flight permissions from the FAA. Many thanks to NOAA AOC Twin Otter pilots and mechanic for their role in completing another successful survey. Thank you to Jim Gilpatrick and Joshua Cutler for their participation conducting surveys on the Twin Otter. Thank you to University of Alaska, Fairbanks and the NOAA Puma operators for testing alternate UASs in 2012. All work was conducted under NMFS ESA/MMPA Permit \#18528 and IUCUC number A/NW2013-2. The findings and conclusions in the paper are those of the author(s) and do not necessarily represent the views of the National Marine Fisheries Service, NOAA. Reference to trade names does not imply endorsement by the National Marine Fisheries Service, NOAA.

\section{References}

Chumbley, K., Sease, J., Strick, M., and Towell, R. 1997. Field studies of Steller sea lions (Eumetopias jubatus) at Marmot Island, Alaska 1979 through 1994. U.S. Dept. of Commer. NOAA Tech. Memo. NMFSAFSC-77. Available From http://www.afsc.noaa.gov/Publications/AFSC-TM/NOAA-TM-AFSC77.pdf [accessed 10 February 2015].

Durban, J., Fearnbach, H., Barrett-Lennard, L., Perryman, W., and LeRoi, D. 2015. Photogrammetry of killer whales using a small hexacopter launched at sea. J. of Unmanned Vehicle Systems. 3(3):131-135.

Fritz, L., Lynn, M., Kunisch, E., and Sweeney, K. 2008. Aerial, ship and land-based surveys of Steller sea lions (Eumetopias jubatus) in Alaska, June and July 2005-2007. U.S. Dept. of Commer. NOAA Tech. Memo. NMFS-AFSC-183. Available From http://www.afsc.noaa.gov/Publications/AFSC-TM/NOAATM-AFSC-183.pdf [accessed 10 February 2015]. 
Fritz, L., Sweeney, K., Johnson, D., and Gelatt, T. 2015. Results of Steller sea lion surveys in Alaska, June-July 2014. Available from the Alaska Fisheries Science Center, Seattle, Wa, pp 1-13. Available from http://www.afsc.noaa.gov/NMML/PDF/SSL_Aerial_Survey 2014.pdf [accessed 10 February 2015].

Fritz, L., Sweeney, K., Johnson, D., Lynn, M., and Gilpatrick, J. 2013. Aerial and ship-based surveys of Steller sea lions (Eumetopias jubatus) conducted in Alaska in June-July 2008 through 2012, and an update on the status and trend of the western stock in Alaska. U.S. Dept. of Commer. NOAA Tech. Memo. NMFS-AFSC-251.

Goebel, M.E., Perryman, W.L., Hinke, J.T., Krause, D.J., Hann, N.A., Gardner, S., and LeRoi, D.J. 2015. A small unmanned aerial system for estimating abundance and size of antarctic predators. Polar Biol. pp:1-12.

Hodgson, A., Kelly, N., and Peel, D. 2013. Unmanned aerial vehicles (UAV) for surveying marine fauna: A dugong case study. PLoS ONE. 8(11): e79556.

Johnson, D.S., and Fritz, L. 2014. agTrend: A Bayesian approach for estimating trends of aggregated abundance. Methods Ecol. Evol. 5(10):1110-1115.

Jones, G.P., Pearlstine, L.G., and Percival, H.F. 2006. An assessment of small unmanned aerial vehicles for wildlife research. Wildl. Soc. Bull. 34(3):750-758.

Moreland, E., Cameron, M., Angliss, R., and Boveng, P. 2015. Evaluation of a ship-based unoccupied aircraft system (UAS) for surveys of spotted and ribbon seals in the Bering Sea pack ice. J. of Unmanned Vehicle Systems. 3(3): 114-122.

NMFS. 2008. Recovery Plan for the Steller sea lion (Eumetopias jubatus) [online], Revision. National Marine Fisheries Service, Silver Spring, Md. Available from http://alaskafisheries.noaa.gov/protectedresources/stellers/recovery/sslrpfinalrev030408.pdf.

NMFS. 2010. Endangered Species Act - Section 7 Consulation Biological Opinion [online]. National Marine Fisheries Service, Silver Spring, Md. Available from http://alaskafisheries.noaa.gov/protectedresources/stellers/esa/biop/final/biop1210_chapters.pdf.

Perryman, W.L., Goebel, M.E., Ash, N., and LeRoi, D.J. 2012. Small Unmanned Aerial systems for estimating abundance of krill-dependent predators: a feasibility study with preliminary results. Southwest Fisheries Science Center field report. NOAA-TM-NMFS-SWFSC-524. Available from https://swfsc.noaa.gov/publications/CR/2014/2014Perryman.pdf [accessed 10 February 2015].

Pitcher, K.W., Burkanov, V.N., Calkins, D.G., Le Boeuf, B.J., Mamaev, E.G., Merrick, R.L., and Pendleton, G.W. 2001. Spatial and temporal variation in the timing of births of Steller sea lions. J. Mammal. 82(4):1047-1053.

Pitcher, K.W., and D.G. Calkins. 1981. Reproductive biology of Steller sea lions in the Gulf of Alaska. J. Mammal. 62(3):599-605.

Pomeroy, P., O’Connor, L., and Davies, P. 2015. Assessing use of and reaction to unmanned aerial systems in gray and harbor seals during breeding and molt in the UK. J. of Unmanned Vehicle Systems. 3(3): 102113.

Sease, J.L., and Gudmundson, C.J. 2002. Aerial and land-based surveys of Steller sea lions (Eumetopias jubatus) from the western stock in Alaska, June and July 2001 and 2002. U.S. Dept. of Commerce, NOAA Tech. Memo. NMFS-AFSC-131. Available from 
381

382

383

384

385

386

387

388

389

390
http://www.afsc.noaa.gov/Publications/AFSC-TM/NOAA-TM-AFSC-131.pdf [accessed 10 February 2015].

Sweeney, K.L., Shertzer, K.W., Fritz, L.W., and Read, A.J. 2015. A novel approach to compare pinniped populations across a broad geographic range. Can. J. Fish. Aquat. Sci. 72(2):175-185.

van Polanen Petel, T.D., Terhune, J.M., Hindell, M.A., and Giese, M.A. 2006. An assessment of the audibility of sound from human transport by breeding Weddell seals (Leptonychotes weddellii). Wildl. Res. 33(4):275-291.

Vermeulen, C., Lejeune, P., Lisein, J., Sawadogo, P., and Bouché, P. 2013. Unmanned aerial survey of elephants. PloS One. 8(2):e54700. 
391 Table

392 Table 1. Number of sites for collecting non-pup and pup counts surveyed from 2000 to 2014, and the percentage 393 of total number of sites, used for modeling abundance trends (excluding those sites with little to no sea lions 394 present since the early 2000s).

395

396 Table 2. Steller sea lion non-pup and pup counts from images captured on Hasgox Point (Ulak Island) obtained

397

398

399

400

by both aerial platforms during the 2014 abundance survey. The non-pup count from the traditional aircraft survey conducted only one day after the hexacopter survey was incomplete due to fog $\left(^{*}\right)$.

\begin{tabular}{lccc} 
& & \multicolumn{2}{c}{ Count } \\
\cline { 3 - 4 } Aerial Platform & Date & Non-pup & Pup \\
\hline Hexacopter & 29-Jun & 391 & 176 \\
Traditional aircraft & 30-Jun & $409^{*}$ & 173 \\
Traditional aircraft & 9-Jul & 371 & 182 \\
\hline
\end{tabular}

\begin{tabular}{|c|c|c|c|c|}
\hline & \multicolumn{2}{|c|}{ "Non-Pup" Sites } & \multicolumn{2}{|c|}{ "Pup" Sites } \\
\hline & $\begin{array}{c}\text { No. } \\
\text { Surveyed }\end{array}$ & $\begin{array}{c}\text { Percentage } \\
\text { of total }\end{array}$ & $\begin{array}{c}\text { No. } \\
\text { Surveyed }\end{array}$ & $\begin{array}{c}\text { Percentage } \\
\text { of total }\end{array}$ \\
\hline 2000 & 123 & 98 & 4 & 12 \\
\hline 2001 & - & 0 & 19 & 56 \\
\hline 2002 & 123 & 98 & 26 & 76 \\
\hline 2003 & - & 0 & 3 & 9 \\
\hline 2004 & 116 & 92 & 27 & 79 \\
\hline 2005 & - & 0 & 29 & 85 \\
\hline 2006 & 85 & 67 & - & 0 \\
\hline 2007 & 85 & 67 & 4 & 12 \\
\hline 2008 & 121 & 96 & 4 & 12 \\
\hline 2009 & 32 & 25 & 33 & 97 \\
\hline 2010 & 89 & 71 & 15 & 44 \\
\hline 2011 & 66 & 52 & 23 & 68 \\
\hline 2012 & 15 & 12 & 5 & 15 \\
\hline 2013 & 15 & 12 & 6 & 18 \\
\hline 2014 & 121 & 96 & 32 & 94 \\
\hline Total & 126 & 100 & 34 & 100 \\
\hline
\end{tabular}




\section{$401 \quad$ Figures Legends}

402

Fig. 1. Aerial images of the Steller sea lion site, East Cape on Amchitka Island captured by the Puma fixed-wing

404 (A), Aeryon Scout quadrocopter (B), and APH-22 hexacopter (C) unoccupied aircraft platforms, and the occupied aircraft (D).

406

Fig. 2. Known terrestrial sea lion sites in Alaska throughout the Aleutian Island chain and the western Gulf of

Alaska. Available airfields are indicated that are accessible to the occupied aircraft which surveyed the Delarof Islands and to the east while the hexacopter focused effort west of the Delarof Islands to Attu Island.

410

Fig. 3. The APH-22 hexacopter system including the 6-rotor aircraft (left), ground station (mounted on the tripod), and the radio control transmitter (bottom, right).

413

Fig. 4. Steller sea lion sites surveyed using the hexacopter (⿳) $)$, conducted from the land (vessel, inflatable skiff offshore, or from a lookout; $\Delta$ ), and the Twin Otter (०), as well as those sites that were missed (+) along the Aleutian Island chain and the western Gulf of Alaska.

417

Fig. 5. Cropped portion of an image captured by the hexacopter at approximately $45 \mathrm{~m}$ altitude showing two animals looking up towards the hexacopter while other remain undisturbed including, a lone marked juvenile (left; 44) and another marked juvenile suckling (uninterrupted) from its mother (upper, right; 82). a marked ( 100) juvenile male clearly visible to the right of a female and pup pair. 

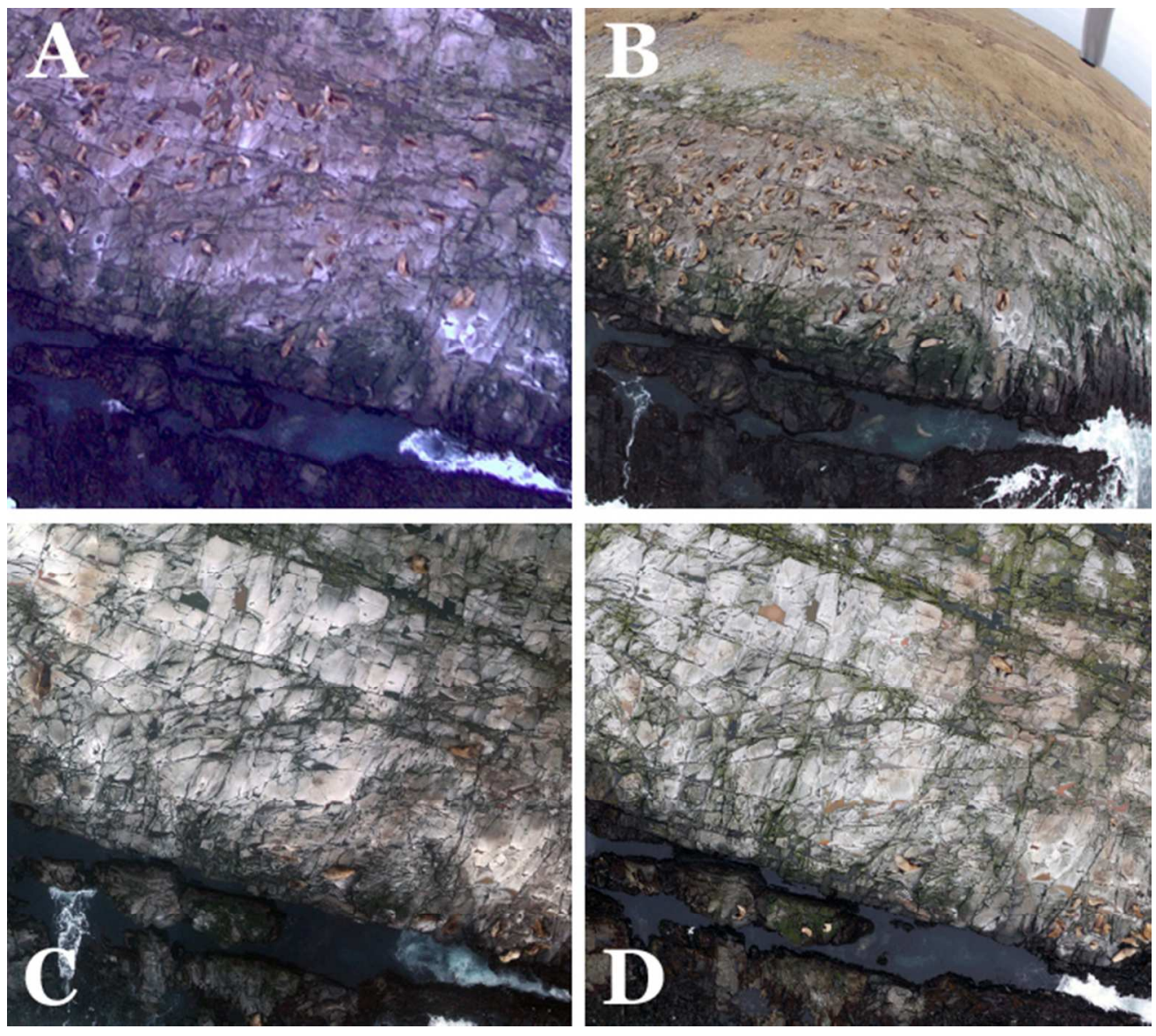

Aerial images of the Steller sea lion site, East Cape on Amchitka Island captured by the Puma fixed-wing (A), Aeryon Scout quadrocopter (B), and APH-22 hexacopter (C) unoccupied aircraft platforms, and the occupied aircraft (D). $249 \times 221 \mathrm{~mm}(72 \times 72 \mathrm{DPI})$ 


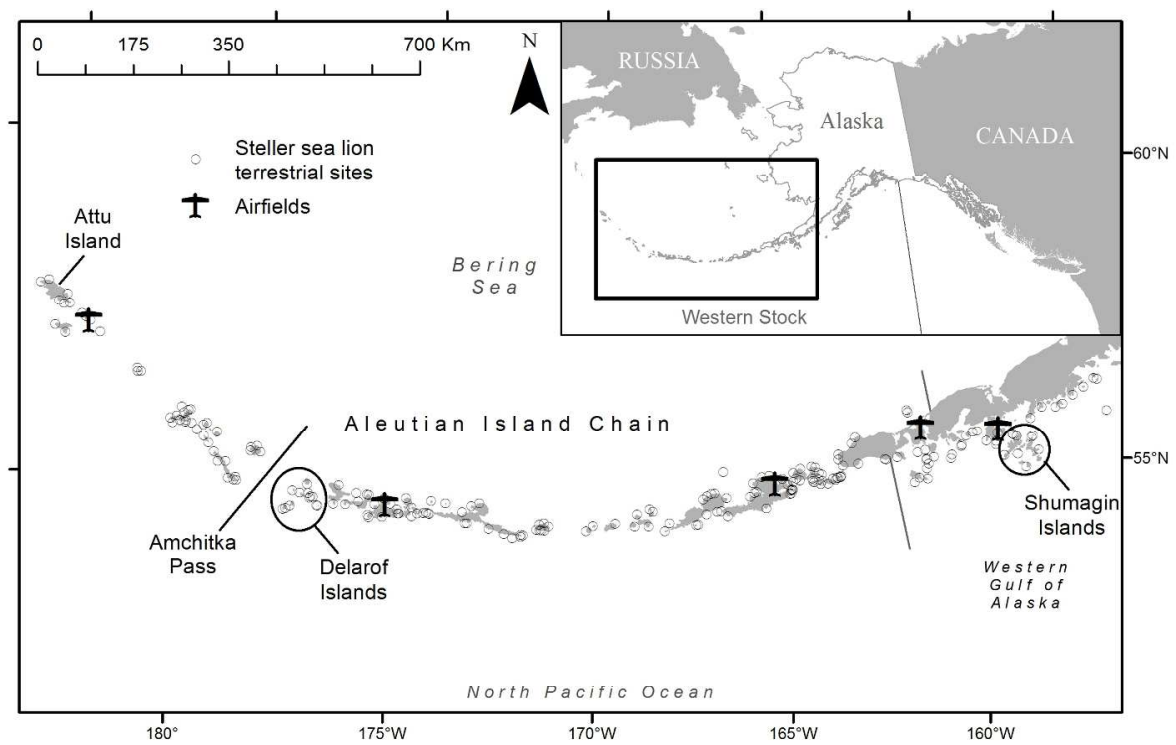

Known terrestrial sea lion sites in Alaska throughout the Aleutian Island chain and the western Gulf of Alaska. Available airfields are indicated that are accessible to the occupied aircraft which surveyed the Delarof Islands and to the east while the hexacopter focused effort west of the Delarof Islands to Attu Island.

$237 \times 162 \mathrm{~mm}(300 \times 300 \mathrm{DPI})$ 


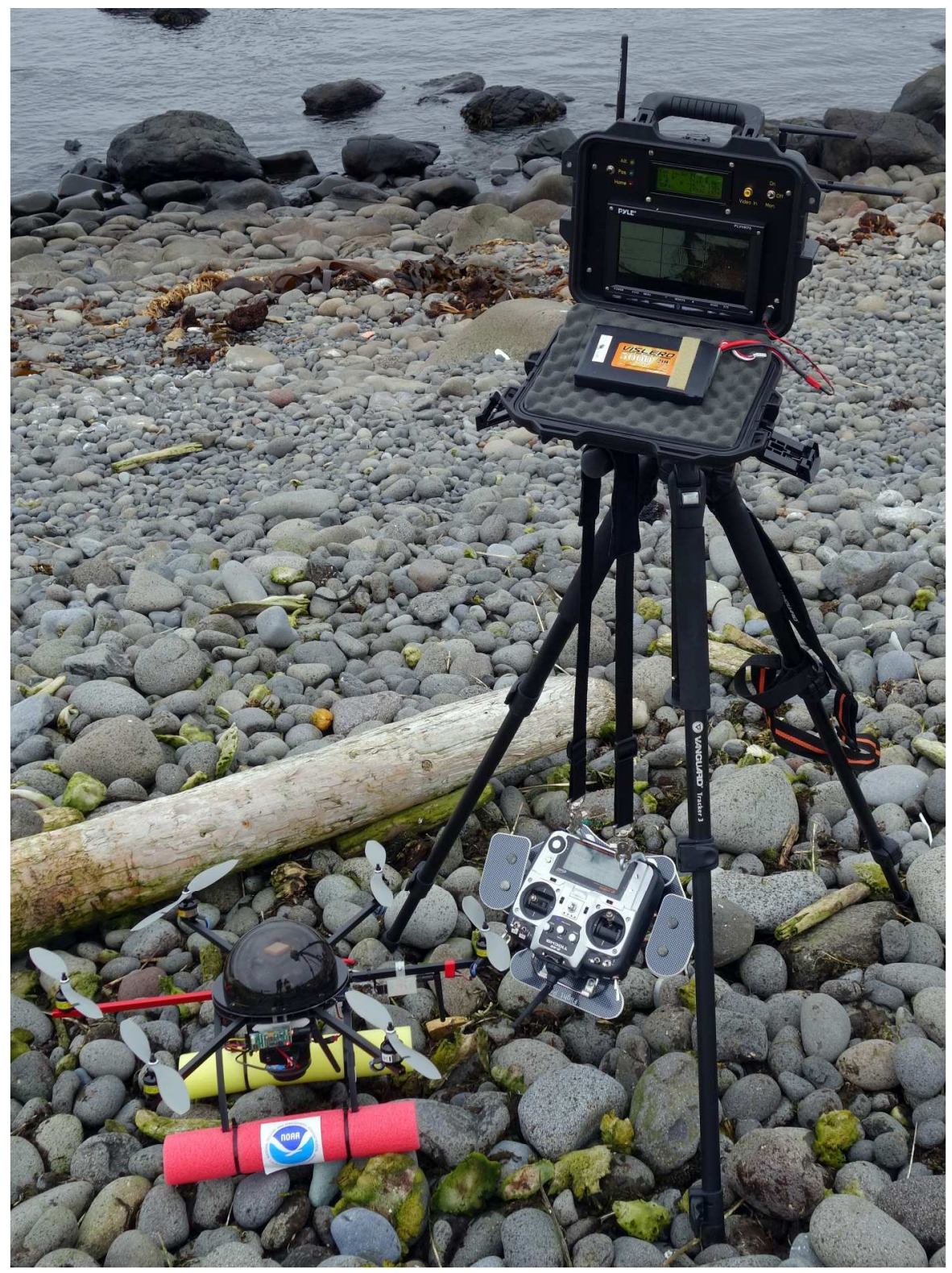

The APH-22 hexacopter system including the 6-rotor aircraft (left), ground station (mounted on the tripod), and the radio control transmitter (bottom, right). $295 \times 397 \mathrm{~mm}(300 \times 300 \mathrm{DPI})$ 


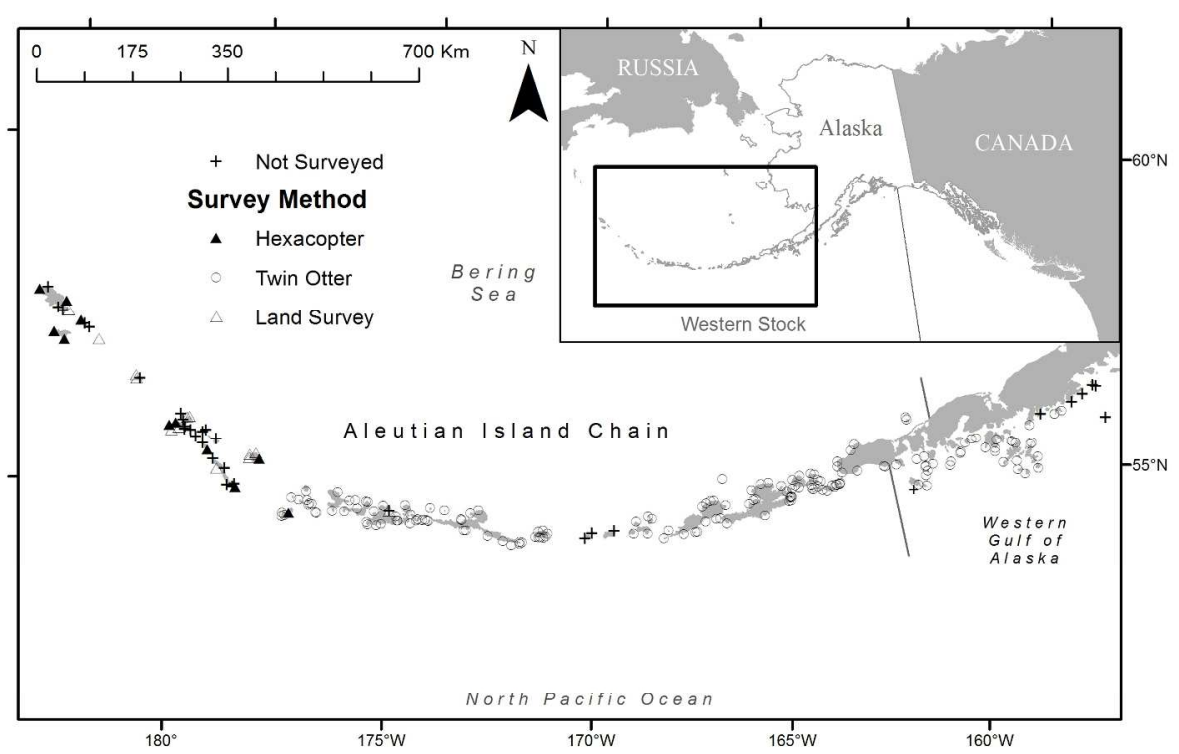

Steller sea lion sites surveyed using the hexacopter ( $)$, conducted from the land (vessel, inflatable skiff offshore, or from a lookout; ), and the Twin Otter ( ), as well as those sites that were missed (+) along the Aleutian Island chain and the western Gulf of Alaska.

$237 \times 162 \mathrm{~mm}(300 \times 300 \mathrm{DPI})$ 


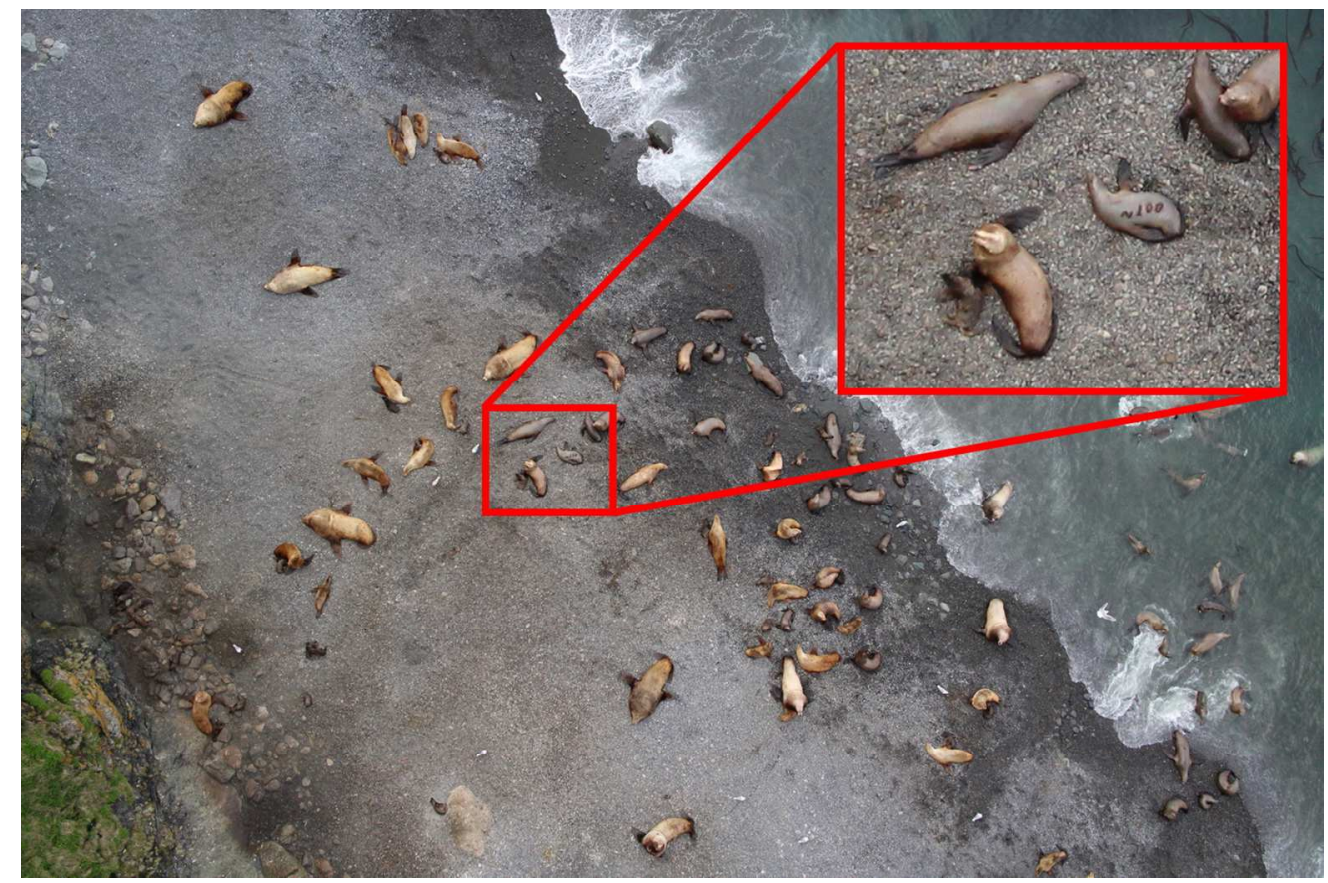

Image captured from the digital camera vertically mounted on the hexacopter at approximately $60 \mathrm{~m}$ with a marked $(\sim 100)$ juvenile male clearly visible to the right of a female and pup pair. $508 \times 338 \mathrm{~mm}(72 \times 72 \mathrm{DPI})$ 